\title{
Tempo e espaço para educação corporal no cotidiano de uma escola pública
}

\author{
Antonio Jorge Gonçalves Soares* \\ Alexandre da Costa Ferreira** \\ Diego Luz Moura*** \\ Tiago Lisboa Bartholo**** \\ Marcos Carneiro da Silva ${ }^{* * * * *}$
}

\begin{abstract}
Resumo: O objetivo é analisar as possibilidades de educação corporal no espaço e tempo das aulas de educação física, treinos, recreios e tempos vagos numa escola pública do Rio de Janeiro. Foram realizadas observações das aulas, dos tempos vagos e dos recreios e entrevistas com alunos e a professora. Conclui-se que o espaço e tempo das aulas não são identificados positivamente, ao menos para grande parcela de alunos. Os motivos estão intrincados numa teia complexa de tensões entre atores da instituição escolar, comunidade que acolhe a escola, diversidade de valores sobre a formação do cidadão e "função" da educação física.
\end{abstract}

Palavras-chave: Observação. Motivação. Educação Física.

\section{INTRODUÇÃO}

O presente estudo analisa o cotidiano das aulas de educação física e das demais atividades corporais praticadas no recreio, nas atividades de treino esportivo e nos tempos vagos numa escola pública do município do Rio de Janeiro. Os objetivos do texto são: observar as possibilidades de fruição corporal dos alunos no espaço e tempo deter-

\footnotetext{
* Doutor em educação física. Docente do PPGEF da Universidade Gama Filho e da UFRJ. Bolsista CNPq. Rio de Janeiro, RJ, Brasil. E-mail: ajsoares@globo.com

** Mestrando em educação física na Universidade Gama Filho. Docente da SME/RJ. Rio de Janeiro, RJ, Brasil. E-mail: xandreferreira@ig.com.br

*** Mestre em educação física pela Universidade Gama Filho e bolsista do CNPq. Rio de Janeiro, RJ, Brasil. E-mail: lightdiego@yahoo.com.br

**** Mestre em educação física e docente do Cap-UFRJ. Rio de Janeiro, RJ, Brasil. E-mail: tbartholo81@hotmail.com

***** Doutor em educação física e docente da UFRJ. Rio de Janeiro, RJ, Brasil. E-mail: m1acs2004@yahoo.com.br
} 
minados para as aulas de educação física, para os treinos esportivos e para os recreios e tempos vagos da Escola Municipal Euzébio Bragança; ${ }^{1}$ descrever e analisar os conflitos e tensões sobre os objetivos da disciplina educação física na referida unidade escolar; descrever e analisar as motivações dos alunos para aderirem às aulas de educação física e às práticas corporais recreativas presentes no dia a dia da escola investigada.

Estudar como a escola concreta organiza seu tempo e espaço ${ }^{2}$ para prática de atividades corporais dos alunos e alunas através dos esportes, dos jogos e das brincadeiras pode nos revelar indícios sobre parte da educação corporal oferecida, intencionalmente ou não, no currículo dessa escola. Essa dimensão educativa presente no tempo e espaço da escola não se restringe à disciplina de educação física. Ela ocorre na instituição escolar em tempos e espaços múltiplos, através dos diferentes dispositivos coercitivos e/ou incentivadores, nos quais os alunos e alunas são mobilizados a aprender a controlar gestos, expressões corporais e linguísticas. Tal processo educativo se realiza de forma sistemática e intencional através de atividades, de disciplinas e de oficinas que privilegiam o ensino sistemático de técnicas corporais (no sentido maussiano) artísticas, esportivas, cívicas, religiosas etc. Noutra direção, sabemos que a educação do corpo ocorre em outros espaços e tempos cujos objetivos não visam, prima facie, ao ensino de técnicas corporais de forma explícita e intencional. Todavia, nesses espaços a educação do corpo se dá, de forma sutil, pela forma que os alunos e alunas são dispostos na sala de aula, pelas possibilidades de movimentação e expressão na escola e pelos constrangimentos operados diretamente sobre os corpos nas diferentes interações que ocor-

\footnotetext{
Os nomes da escola e dos atores citados são fictícios.

${ }^{2}$ A organização espaço-temporal das escolas brasileiras foi baseada fundamentalmente para pensar o ensino de conteúdos formalizados pelas disciplinas. Com isso, a dimensão espacial, os lugares do ensino não foram pensados como lugares e tempos das diferentes crianças e adolescentes que frequentam a escola. Em nossa análise, estamos preocupados com a ocupação temporal e gestão dos espaços pensados para aulas de educação física, dos recreios e dos horários livres de disciplinas na escola (tempos vagos). Partimos do pressuposto de que a gestão do tempo e do espaço influencia na formação das subjetividades dos alunos. Na Crítica da Razão Pura (1971), Kant apresenta espaço e tempo como instituições puras a priori, ou seja, são objetos da experiência possível, alçáveis no nível dos sentidos já disponíveis nas instituições de espaço e tempo. Nesse sentido, a organização e gestão dos diferentes tempos e espaços escolares formam e conformam as subjetividades de alunos e professores.
}

Movimento, Porto Alegre, v. 16, n. 01, p. 71-96, janeiro/março de 2010. 
rem no cotidiano. Em outras palavras, os alunos e alunas aprendem pelo corpo normas e valores, sem palavras, pelos dispositivos organizados nesse tempo e espaço (BOURDIEU, 1990). De fato, o tempo e o espaço na vida escolar não são dimensões neutras do ensino escolar, eles indicam que tais dimensões instituem uma discursividade sobre valores e sobre um conjunto de aprendizagens sensoriais e motoras (FARIA FILHO, VIDAL, 2000; PETITAT, 1989).

Em termos metodológicos, realizamos observações diretas das aulas de educação física, dos recreios e dos tempos vagos, totalizando um total de 800 minutos. Tais observações foram registradas em diário de campo. Também foram realizadas entrevistas com alunos e com a professora de educação física responsável pelas turmas observadas.

\section{Cultura escolar, esPorte E EDUCAÇÃo FísicA}

No campo acadêmico da educação, tornou-se lugar comum para os estudos culturais marcar o argumento de que a instituição escolar possui uma cultura que lhe é própria e específica. Parece lógico que a força desse argumento não é a de proclamar um relativismo radical sobre a singularidade da instituição escolar. A escola, apesar de possuir uma cultura que "lhe é própria", não se situa num vazio sociológico e nem possui uma singularidade deslocada do contexto no qual está inserida. A ressalva se faz necessária na medida em que não queremos entender o conceito de cultura como argumento retórico. Afinal, se entendêssemos cada instituição escolar com uma cultura única e singular, perderíamos a possibilidade de comparação e generalização, princípio fundamental da pesquisa. Sendo assim, o termo cultura ${ }^{3}$ é entendido nesse estudo como um conjunto de disposições e valores, não homogêneos, internalizados pelos atores de uma determinada unidade social na qual atuam em interação num espaço de luta para afirmar significados de permanência e mudança em constante diálogo com o jogo social mais amplo. Nesse sentido, o tempo e o espaço na vida escolar não são dimensões neutras, pois instituem discursividades sobre valores e sobre um conjunto de aprendizagens sensoriais e motoras. (FARIA FILHO; VIDAL, 2000).

\footnotetext{
${ }^{3}$ Cuche (2002) e Kupper (2002) descrevem as diferentes apropriações do termo cultura.

Movimento, Porto Alegre, v. 16, n. 01, p. 71-96, janeiro/março de 2010.
} 


\section{4}

Artigor Originair Antonio Jorge Gonçalves Soares et al.

Nessa direção, a Escola Municipal Euzébio Bragança, localizada no Complexo do Alemão, região controlada por facções do tráfico de drogas que lutam constantemente pelo controle das áreas de venda de drogas e que tem um dos índices de desenvolvimento humano (IDH) mais baixos $(0,587)$, deve ser pensada a partir desse entorno. Observemos que o Brasil como um todo apresenta índice de $0,792 .{ }^{4}$ Grande parte da má avaliação da região se dá pelos altos índices de homicídio, principalmente entre os jovens. Esse contexto de violência interfere no cotidiano escolar com a suspensão de aulas nos dias de intenso confronto entre policiais e traficantes. Esse clima gera tensão constante em toda a comunidade escolar, que se vê obrigada a adaptar sua rotina diária ao contexto externo e a dialogar com os problemas que ocorrem em seu entorno. Estes apontamentos corroboram o que Macedo (2006) aponta como principal objetivo dos estudos sobre currículo, ${ }^{5}$ ou seja, buscar compreender as relações entre as restrições e as possibilidades de ações no espaço escolar como paradoxos.

Pode-se dizer que a má gestão escolar auxiliou também, por influência de uma perversa cultura do funcionalismo público, a dessacralizar a atividade do magistério e a desorganizar o tempo da escola. Por exemplo, o "tempo vago", em função das faltas e licenças de professores da rede pública, ${ }^{6}$ acabou por instaurar esse tempo destinado para brincadeiras, esportes e outras propostas de atividades como um lugar de exercício da sociabilidade entre alunos sem nenhuma mediação pedagógica. Não estamos propondo que todos os "tempos" sejam controlados a partir de uma perspectiva pedagógica, todavia, há que se destacar que o tempo destinado às disciplinas acaba sendo apropriado por outras atividades não programadas no interior da escola.

Além desses fatores que influenciam o uso do tempo e do espaço na escola, temos fatores específicos que exercem influência direta sobre o que deve ser ensinado ou praticado nas aulas de educação física,

\footnotetext{
${ }^{4}$ Disponível em: www.wsws.org/pt/2007/jul2007/fave-j04.shtml. Acesso em: 14 de nov. 2007. ${ }^{5}$ Macedo (2006) entende como currículo os registros de memórias, documentos e experiências vivenciadas por instituições escolares.

${ }^{6}$ Não estamos afirmando que o funcionalismo público em geral assume o descompromisso com a escola. Todavia, sabemos que a engenharia da administração escolar não prevê prêmios para os bons funcinários e também não aplica na prática punições aos que são descompromissados com suas tarefas profissionais.

Movimento, Porto Alegre, v. 16, n. 01, p. 71-96, janeiro/março de 2010.
} 
bem como os treinos das equipes escolares, nos recreios e nos tempos vagos. O esporte certamente é um desses sistemas sociais que exercem reflexibilidade sobre as ações de alunos e professores nos tempos e atividades supracitadas. A escola, para além dos valores do saber de caráter instrumental e propedêutico dos conteúdos de ensino, é um lugar para novas gerações se expressarem e se apropriarem de experiências de sociabilidade. ${ }^{7} \mathrm{O}$ esporte, apesar de gerar no interior da escola demandas diferenciadas por parte dos(as) alunos(as), é um dos meios de educação do corpo ${ }^{8}$ para o lazer.

O problema é que a educação física, nas diferentes abordagens produzidas sobre o fenômeno esportivo, revela falta de consenso ou acordos mínimos sobre seus objetivos e conteúdos de ensino na escola (LOVISOLO, 2000).

\section{CONHECENDO O CAMPO OBSERVADO}

A Escola Municipal Euzébio Bragança fica localizada na periferia do município do Rio de Janeiro, entre as favelas da Nova Brasília e Fazendinha, ambas as comunidades pertencentes ao complexo de favelas do Alemão. ${ }^{9}$ A escola onde foi realizado o estudo pertence à $3^{\circ}$ Coordenadoria Regional de Ensino (CRE), localizada no bairro de Inhaúma, que possui sob sua adminsitração 19 escolas. Todavia, essa gigantesca comunidade é atendida por outras escolas dos bairros de Bonsucesso, Ramos e Olaria que se encontram nas proximidades do Complexo do Alemão e não estão sob a jurisdição dessa CRE.

A escola possui 799 alunos distribuídos em turmas de $1^{\circ}$ e $2^{\circ}$ segmentos do Ensino Fundamental. A unidade possui ainda um corpo administrativo composto de: uma diretora-geral, uma diretora-adjunta, duas secretárias e uma coordenadora pedagógica. Já o corpo docente

\footnotetext{
7 Utillizamos aqui o conceito de acordo com Simmel.

${ }^{8}$ Entendemos como educação do corpo para o lazer todas as atividades físicas oferecidas no espaço escolar ou em outras instituições que estejam voltadas para a educação do gesto ou do movimento seja na busca da excelência e/ou rendimento, seja como constituição de um espaço de recreação.

${ }^{9}$ O Complexo do Alemão está localizado na Zona Norte da cidade do Rio de Janeiro, entre os bairros de Ramos, Olaria, Inhaúma e Bonsucesso. O Complexo é formado por 12 comunidades carentes e possui uma população estimada em 300.000 habitantes.

Wovimento, Porto Alegre, v. 16, n. 01, p. 71-96, janeiro/março de 2010.
} 
da instituição é constituído por quarenta e seis professores, sendo dois de educação física. O funcionamento da unidade escolar Euzébio Bragança é dividido nos turnos da manhã e da tarde. Entre o terceiro e quarto tempos de ambos os turnos acontece o recreio com duração de vinte minutos.

A escola está edificada num prédio com dois andares onde se localizam: as salas de aula, a secretaria, o refeitório e a sala dos professores. Na parte externa, encontramos os espaços que são utilizados para a prática de jogos populares e esportivos, seja nas aulas de educação física, seja durante os recreios e tempos vagos, a saber: uma quadra coberta com aproximadamente trinta metros de comprimento e vinte metros de largura, cercada por uma tela de proteção. A quadra contém ainda duas balizas e duas tabelas de basquete. A superfície da quadra é áspera, porém sem irregularidades, e nela observamos de forma bem apagada as linhas que demarcam o espaço de jogo de basquetebol, de handebol e de futsal. Os espaços entre a quadra e os muros da escola também são utilizados para a prática de jogos e brincadeiras.

A disciplina de educação física conta com dois professores, a professora Marta e o professor Jorge Wagner. Todavia, as observações foram realizadas apenas nos dias de aula da Professora Marta. Foi ela quem permitiu a entrada no campo de observação, além de ter sido sempre muito solícita com as questões referentes à pesquisa. Ela atua na área do magistério desde 1975 na qualidade de $\mathrm{PII}^{10} \mathrm{e}$, após 1994 assumiu o cargo de PI. ${ }^{11}$ Em 1972, incentivada pelo seu marido, também professor de educação física, inicia o curso de educação física, concluindo em 1976. Em 1994, após ser aprovada em um processo seletivo para professor de educação física da Rede Municipal do Rio de Janeiro, a professora Marta abandona o cargo de PII e começa a lecionar a disciplina de educação física.

\footnotetext{
${ }^{10} \mathrm{PII}$ é a designação adotada pela Secretaria de Educação do Município do Rio de Janeiro para denominar os professores que atuam no $1^{\circ}$ segmento do Ensino Fundamental.

${ }^{11} \mathrm{PI}$ é a designação adotada pela Secretaria de Educação do Município do Rio de Janeiro para denominar os professores que atuam no $2^{\circ}$ segmento do Ensino Fundamental e do programa de educação de jovens e adultos.

Movimento, Porto Alegre, v. 16, n. 01, p. 71-96, janeiro/março de 2010.
} 


\section{DADOS E ANÁLISES DO TRABALHO DE CAMPO}

Durante o período da observação, constatamos que o conteúdo principal abordado nas aulas, independente da seriação, é o esporte de quadra, tais como: futebol, handebol, voleibol e basquetebol.

O jogo esportivo, mais ou menos inspirado nas regras oficiais dos esportes coletivos (futebol, handebol, voleibol e basquetebol), é a estratégia pedagógica utilizada pela professora no processo de transmissão de conteúdos. ${ }^{12}$ Nesta pesquisa, foram observadas três aulas de cada uma das turmas a seguir relacionadas: uma turma de $4^{\circ}$ série/ $5^{\circ}$ ano (402), duas turmas de $5^{\circ}$ série $/ 6^{\circ}$ ano (502 e 504) e uma turma de 6 série $/ 7^{\circ}$ ano (603). A turma 402 possui um total de 24 alunos. A turma 502 possui um total de 36 alunos. A turma 504 possui um total de 37 alunos e a turma 603 possui um total de 43 alunos.

Para cada aula foi realizado um levantamento do número de alunos presentes e participantes, presentes e não-participantes e ausentes. Os números obtidos são contemplados na tabela abaixo:

\begin{tabular}{|c|c|c|c|}
\hline Turmas observadas & $\begin{array}{c}\text { Total de alunos presentes } \\
\text { e participantes (\%) }\end{array}$ & $\begin{array}{c}\text { Total de alunos presentes } \\
\text { e não participantes (\%) }\end{array}$ & $\begin{array}{c}\text { Total de alunos ausentes } \\
\text { (\%) }\end{array}$ \\
\hline 402 & 44,4 & 41,7 & 13,9 \\
\hline 502 & 44,4 & 38,9 & 16,7 \\
\hline 504 & 57,6 & 27,9 & 14,4 \\
\hline 603 & 49,5 & 33,5 & 17,0 \\
\hline Total & $\mathbf{4 8 , 9}$ & $\mathbf{3 5 , 5}$ & $\mathbf{1 5 , 5}$ \\
\hline
\end{tabular}

Tabela 1 - Números referentes à média de participações e ausências ao término das observações

Em relação ao significativo porcentual de alunos ausentes durante as aulas (15,5\%), cabe lembrar que a localidade onde a escola está inserida sofre forte controle do tráfico de drogas. Portanto, quando ocorrem incursões policiais nas favelas próximas à unidade, os alunos ficam impedidos de ir à escola devido à intensa troca de tiros entre traficantes e policiais. As falas da professora Marta retratam bem o problema:

\footnotetext{
${ }^{12}$ Esse método utilizado pela professora durante o processo de ensino e aprendizagem é descrito por Dietrich, Dürrwächter e Schaller (1984) como método de confrontação. Segundo os autores citados, essa concepção metodológica renuncia a um desmembramento do jogo em elementos isolados e a um alinhamento didático desses elementos. Nesse método, formam-se duas equipes e coloca-se rapidamente, com poucas instruções, um jogo em andamento sob o lema: jogar e jogar. Esse método utilizado pela professora é muito similar ao que se observa durante as práticas não-dirigidas realizadas pelos alunos nos recreios e tempos vagos.
}

Movimento, Porto Alegre, v. 16, n. 01, p. 71-96, janeiro/março de 2010. 
"Hoje a frequência está baixa, está tendo problema lá em cima." (Diário de campo, 31/10/2006).

"Semana passada perdemos três dias de aula por conta dessa guerra aí fora, mandam fechar a escola e eles (referindo-se aos discentes) ficam pela rua... está tudo errado." (Diário de campo, 25/10/2007).

Aqui temos um exemplo de como o tempo escolar dessa escola é influenciado diretamente pela violência estrutural vivida mais intensamente em alguns bairros e regiões da cidade do Rio de Janeiro. Destaque-se que o número de $15 \%$ de alunos faltosos é significativo se pensarmos o papel da escola na vida desses jovens. A lição de que o tempo da escola ainda não se impôs na sociedade brasileira como um todo vale para esse caso.

Os dados anteriores, sob a perspectiva da participação dos alunos no tempo e no espaço das aulas de educação física, podem revelar indícios sobre os problemas enfrentados por essa disciplina nessa escola específica. No entanto, há de se perguntar: tais problemas são específicos dessa escola? Destaquemos que $35,5 \%$ dos alunos presentes no espaço e no tempo das aulas de educação física, das quatro turmas observadas durante o trabalho de campo, assumiram o papel de espectadores das atividades propostas. Esse número pode ser considerado preocupante na medida em que a missão da educação escolar é universalizar experiências e conhecimentos. Todavia, tais problemas em relação à participação das aulas estão longe de ser específicos dessa escola. Outras pesquisas ${ }^{13}$ sobre a educação física escolar, em

\footnotetext{
${ }^{13}$ Calado (2003) comparou o índice de absenteísmo entre as disciplinas de educação física, história e matemática, nas fichas de registro anual das turmas e verificou que a educação física apresentou um alto índice, comprovando a necessidade de um estudo mais aprofundado das suas causas. $\mathrm{Na}$ primeira série, a educação física aparece com um índice de absenteísmo de $9,1 \%$, história com $12,2 \%$ e matemática, $4,8 \%$.Na $2^{\mathrm{a}}$ série, o índice da educação física alcançou a marca de $19,4 \%$, a história $20,1 \%$ e a matemática o patamar de $10,4 \%$. Comparando com os índices da $1^{\text {a }}$ série, observamos que eles dobraram de percentual em educação física e matemática, com um considerável aumento em história. Em relação à $3^{a}$ série, os índices apresentaram a educação física com $21,2 \%$; a disciplina história atingiu $16,0 \%$ enquanto a matemática ficou com $8,8 \%$. Percebemos que na educação física, se comparado com a $2^{\mathrm{a}}$ série, ocorreu um pequeno aumento no índice, já em história e matemática houve uma redução do percentual. Pensamos que esse decréscimo em matemática e história seja em função de seus conteúdos atenderem às necessidades dos alunos para o vestibular. No que se refere ao crescente aumento do índice da educação física, desde a $1^{\text {a }}$ série, acreditamos que esse fato ocorra, primeiramente, porque os alunos sedimentaram o processo de conhecimento institucional e, depois, devido aos conteúdos da disciplina não serem relevantes para os seus objetivos escolares. Trabalhos que tocam, direta ou indiretamente, desenvolvidos no interior de nosso grupo de pesquisa, Costa (2004) e Trotte (2005).
}

Movimento, Porto Alegre, v. 16, n. 01, p. 71-96, janeiro/março de 2010. 
instituições escolares com perfis institucionais e organizativos bem diferentes, também revelam um grau significativo de absenteísmo nas aulas dessa disciplina, se comparada com disciplinas de caráter propedêutico. Devemos refletir que essa ausência de participação no tempo efetivo das aulas de educação física se faz notar pela natureza das atividades que exigem objetivamente fruição corporal dos alunos, em contrapartida, na maioria das disciplinas o baixo nível de participação pode atingir as mesmas proporções e não ser notado. Na educação física, a "comprovação" do professor de que os alunos estão participando ou gostando da atividade está ligada à exposição e à expressão do corpo em deslocamento, enquanto na maioria das disciplinas escolares os alunos podem estar desligados da atividade escolar sem que se altere a disposição dos corpos na sala de aula. Em geral, na escola brasileira - por mais generalizante que seja esse argumento - a maioria das disciplinas e a cultura do magistério relegam o aluno a uma posição de ouvinte passivo nesse espaço e tempo que pouco oportuniza a experimentação e o estudo.

Mesmo entendendo que o problema da participação pode não ser restrito ao âmbito disciplinar, questionamos os alunos não-participantes sobre os motivos da não-adesão às aulas de educação física. A análise das respostas possibilitou agrupar os alunos não-participantes em quatro diferentes grupos: o grupo I, este é constituído por alunos que justificam a não-participação por falta de afinidade com a professora; o grupo II justifica a não-participação pela falta de uniforme; o grupo III alega que não participa por falta de gosto pela disciplina, e por fim, o grupo IV, que justifica a ausência por discordar do conteúdo de ensino abordado durante as aulas. Analisamos de forma separada os argumentos apresentados pelos diferentes grupos sobre as suas nãoparticipações nas aulas de educação física.

Os alunos inseridos no grupo I apontam a falta de afinidade com a professora como sendo fator preponderante para as suas ausências nas aulas de educação física.

\footnotetext{
"Com ela não dá não (referindo-se à professora), ela é muito cheia de marra, é muito grossa." (Informante 5 - sexo feminino).
}

Movimento, Porto Alegre, v. 16, n. 01, p. 71-96, janeiro/março de 2010. 
"A professora do outro ano era muito mais legal, ela não dava esporro." (Informante 9 - sexo feminino).

"É só a gente fazer qualquer coisinha que ela fica gritando e tira da aula." (Informante 15 - sexo feminino).

Parece que as normas baseadas em medidas punitivas ${ }^{14}$ estabelecidas pela professora a fim de manter a ordem e a disciplina durante as aulas podem estar gerando efeitos perversos na relação pedagógica. Observemos que os alunos assumem o lugar de observadores passivos da aula, segundo seus relatos, em função da relação que travam com as normas assumidas pela professora durante as aulas. Noutra direção, a não-participação nas aulas só ocorre, apesar das vozes críticas dos alunos, porque existem dispositivos de tolerância nessa relação pedagógica travada.

Esse quadro que apresenta como reação dos alunos a saída da aula em crítica à postura pedagógica da professora talvez indique a necessidade permanente de repensar as estratégias de construção de normas nos diferentes tempos vividos por docentes e alunos na escolarização. Nesse sentido, Lovisolo alerta:

Os educadores devem revisar as normas em interação com as crianças, levando em consideração seus efeitos positivos e negativos. A reflexão sobre as normas é, ou deveria ser, uma dimensão significativa da educação contemporânea, tanto em termos de justiça quanto de utilidade, já que um dos objetivos básicos da norma é organizar a vida escolar. (LOVISOLO, p. 74, 1997).

O Grupo II é constituído por alunos que justificam a não-participação nas aulas devido à falta do uniforme: ${ }^{15}$

\footnotetext{
"Eu até gosto de fazer mas a professora não deixa fazer sem uniforme."

(Informante 6- sexo masculino).

"Eu faço, às vezes, mas hoje estou sem uniforme." (Informante 7 - sexo feminino.)
}

\footnotetext{
${ }^{14}$ As medidas punitivas impostas pela professora durante as aulas vão desde advertências verbais até as expulsões das aulas.

${ }^{15}$ Segundo a professora, o uniforme de educação física é composto de short preto ou azul-marinho e camisa branca.

Movimento, Porto Alegre, v. 16, n. 01, p. 71-96, janeiro/março de 2010.
} 
"Eu esqueci a bermuda na cama e sem ela, ela não deixa fazer." (Informante 12 - sexo masculino.)

Observemos que a valorização e utilização do uniforme, não só nas aulas de educação física, foi, durante quase todo o Séc. XX, um traço fundamental da cultura escolar nas escolas municipais e estaduais no Rio de Janeiro e em muitas escolas privadas dessa cidade. ${ }^{16}$ O uniforme podia significar várias coisas e tais significados podiam variar entre os tipos de escola. Em geral, o uniforme representava um símbolo de identidade da escola, de hierarquia etária e de grau de escolaridade entre os estudantes (dependendo dos detalhes apresentados visivelmente nas roupas) e de controle público do tempo dos estudantes no trajeto de casa para a escola etc. Independente dos múltiplos fatores surgidos na sociedade contemporânea que tenham levado as escolas em geral a secundarizarem controle sobre a forma e os detalhes de vestir os corpos dos estudantes, o que está em jogo é que a escola perdeu parte do controle que exercia sobre os corpos dos estudantes. Hoje, num mundo que reivindica cada vez mais direitos à identidade e à individualidade, o uniforme passa a ser encarado, em determinadas circunstâncias, como uma imposição fora de lugar ou como mecanismo limitador da expressão do eu. Todas as tentativas de reintroduzir na cultura escolar o controle rígido sobre o uniforme vai buscar racionalizações na economia de custos para os pais, na homogeneização dos alunos no sentido de reduzir a emulação no cotidiano da escola através do consumo de marcas da moda, na revitalização de rituais no espaço escolar ou ainda na segurança dos próprios alunos - que estariam identificados no espaço da "rua" como estudantes.

Nas aulas de educação física, o uniforme ou as roupas adequadas ao exercício físico representam um valor específico na medida em que a disciplina é representada como um dos tempos escolares em que se deve tratar o conteúdo da higiene corporal. Todavia, sabemos que a maioria das escolas públicas não apresenta condições e infraestrutura de vestiários e nem um tempo específico, integrado ao tempo da grade

\footnotetext{
${ }^{16} \mathrm{Um}$ dos autores desse texto foi aluno da Escola Municipal do antigo Estado da Guanabara num bairro popular e nos anos oitenta iniciou suas atividades de magistério na rede pública e privada de ensino.
}

Wovimento, Porto Alegre, v. 16, n. 01, p. 71-96, janeiro/março de 2010. 
curricular, para que os alunos realizem a higiene corporal necessária após os exercícios físicos. Por outro lado, o não uso do uniforme ou os esquecimentos sistemáticos deste, excetuando os problemas de ordem prática (falta de dinheiro, desorganização da vida familiar etc), podem ser pensados como expressão das subjetividades dos jovens ou revelar simplesmente uma crítica de como essa disciplina está instituída no cotidiano dessa escola. Aqui as ausências podem também revelar algo diretamente associado ao vestir o corpo e a como os alunos desejam ou não que seus corpos sejam expostos. Esse é um tema que carece mais estudos empíricos para entender o vestir o corpo no espaço e tempo da escola com algo a ser problematizado pedagogicamente sem os preconceitos habituais que esse tema suscita.

Noutro sentido, poder-se-ia ler as ações da professora, de fazer valer a norma do uso do uniforme, no contexto de precariedade material em que trabalha, como uma forma, consciente ou não, de dimensionar o tamanho da turma em função da infraestrutura e do material pedagógico que possui.

O grupo III é constituído por alunos que alegam não gostar da disciplina educação física.

\footnotetext{
"Eu não gosto muito de [educação] física. Jogar bola não é comigo, prefiro ficar aqui sentada." (Informante 16 - sexo feminino).

"Eu não gosto de física não, ficar para lá e para cá é sem graça." (Informante 13- sexo feminino).

"Física é muito chato, lá em cima é melhor" (referindo-se às outras disciplinas, cujas aulas são ministradas no prédio da escola). (Informante 14 - sexo feminino).
}

Cabe ressaltar que a professora Marta vê a participação dos alunos nas aulas de educação física como sendo facultativa, deste modo, cabe ao aluno a decisão de sua participação. Segundo a professora Marta, ${ }^{17}$ a aula de educação física é um espaço reservado àqueles

\footnotetext{
17 "Às vezes eu até cobro a participação deles, coloco para fazer cópias, mas você sabe como é, não adianta forçar. Então, eu prefiro assim: faz quem gosta." (Diário de campo, 31/10/2006. Fala da professora Marta).

Movimento, Porto Alegre, v. 16, n. 01, p. 71-96, janeiro/março de 2010.
} 
alunos que gostam da disciplina. Deste modo, observamos que a atitude da referida professora - e essa atitude deve ser mais comum do que se imagina nas diferentes escolas - revela o diálogo que a educação física estabelece com as diferentes formas de educação corporal para o lazer em nossa sociedade. Em outras palavras, o esporte ou determinados exercícios físicos requerem o mínimo de habilidade corporal e dependem do gosto e do talento. O talento é uma caixa preta que revela a profecia após o milagre ocorrido. Como impor o gosto e obrigar os não talentosos? Esse tipo de questão revela que a educação física ainda é entendida mais como um espaço de catarse e alívio das pressões que do que como um espaço de conhecimento e aprendizagem. Aqui a educação física atua com uma linguagem diferente da maioria das disciplinas escolares. As demais disciplinas parecem balizar seus discursos a partir da linguagem da norma e da utilidade. Neste sentido, os argumentos para aqueles que não gostam ou não querem se combinam criando um misto de coerção - com a ameaça da reprovação - e do convencimento sobre a importância do conhecimento para sua inserção no mercado profissional. A fala da professora Marta parece destacar um dos dilemas do campo da educação física na atualidade: por um lado, a disciplina continua com seu discurso vitimista em busca de legitimidade no campo escolar. Aqui temos o esforço da disciplina em se enquadrar à lógica disciplinar da escola. Por outro, temos professores, como Marta, que permitem que a participação dos alunos seja facultativa. Argumentos como "não gosto", "não quero", "estou cansado" são aceitos. Nesse caso, a educação física escolar se distancia da lógica das demais disciplinas escolares.

Observe que não estamos aqui julgando moralmente esse distanciamento, mas apontando-o como algo que deva ser problematizado na escola, isto é, todas as disciplinas devem estar sob o mesmo enquadramento no tempo e espaço do currículo? Essa é uma questão que parece assolar o cotidiano das aulas de educação física nessa e em outras escolas. Aqui, o tempo e o espaço dessa disciplina acabam por adotar dispositivos de participação em total sintonia com as imagens e representações do esporte na sociedade, isto é, uma atividade que seus praticantes gostam e para a qual possuem talento e/ou autodisciplina para obter sucesso. Em contraposição, esse dispositivo adotado nas

Wovimento, Porto Alegre, v. 16, n. 01, p. 71-96, janeiro/março de 2010. 
aulas de educação física se contrasta com a legislação em vigor que entende a frequência e participação nas disciplinas curriculares, com exceção da educação religiosa, como obrigatória. Aqui temos um típico exemplo de como a cultura é gestada no interior das instituições escolares específicas e atua em permanente diálogo com outras instituições sociais para além das normas previstas na legislação de ensino.

Cabe ainda uma observação, todas as vozes que indicam não gostar de participar das aulas de educação física são das meninas. Devemos tomar esse dado como um indício para observar o papel do gênero na participação das aulas de educação física a partir das coerções culturais impostas aos(às) alunos(as) no contexto em que estão inseridos(as). A experiência indica que as meninas, após entrarem na adolescência, no sentido corriqueiro do termo, passam a incorporar disposições mais rígidas em relação à apresentação de seus corpos em público. A educação física na escola passa nesse caso a ser uma atividade que cria problemas com os investimentos que as meninas realizam na apresentação de seus corpos no espaço da escola.

Noutra direção, devemos lembrar que o campo da educação física escolar no Brasil, na década de oitenta, condenou a divisão por sexo nas aulas como expressão de ruptura com um modelo de educação física que baseava sua pedagogia nas diferenças sexuais em relação ao desempenho físico. Esse modelo de educação física estava em continuidade com o modelo cultural de organização do esporte institucionalizado, sendo assim, a educação física Progressista ou Renovada dos anos 1980 criou algumas descontinuidades com a cultura esportiva. Hoje, uma nova questão surge entre os estudiosos de gênero no campo: as aulas mistas aumentam ou diminuem a segregação das meninas nesse espaço pedagógico? Para além dessas possibilidades de interpretação, devemos pensar que outros problemas como faixa etária e as formas de socialização podem ter relação com as representações e ações das meninas nesse espaço e tempos pedagógicos.

O grupo IV é constituído por alunos que relatam não aderirem às aulas devido à falta de opções de atividades que lhes são oferecidas.

"Eu não gosto muito não, mas às vezes tenho até vontade de fazer, mas eu não gosto muito de jogar handebol." (Informante 4 - sexo feminino).

Movimento, Porto Alegre, v. 16, n. 01, p. 71-96, janeiro/março de 2010. 


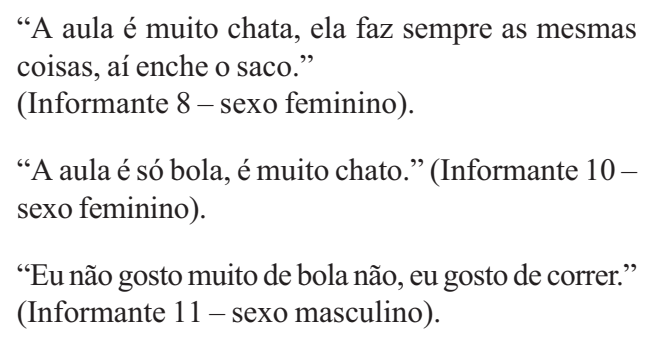

Sobre esta justificativa, verificamos que esses alunos relatam discordar do conteúdo de cunho puramente esportivo abordado durante as aulas de educação física e, por isso, dizem não terem motivação para participar. Percebemos, deste modo, que a aula de educação física, nessa escola e em outras, apresenta pouca variação de conteúdos (BASSANI; TORRI; VAZ, 2005). Mesmo sob todo o apelo midiático do fenômeno esportivo, podemos pensar que as demandas de formação corporal para o lazer são mais variadas do que aquelas padronizadas na maioria das escolas.

\section{As EQUIPES ESPORTIVAS DA ESCOLA}

A Escola Municipal Euzébio Bragança tradicionalmente participa dos Jogos Estudantis, ${ }^{18}$ nas modalidades futsal e handebol. Porém, no ano de 2006, motivada pela boa participação das equipes de handebol no ano anterior, a escola decidiu dedicar um tempo maior ao treinamento desta modalidade. Em 2006, a escola formou três equipes de handebol: uma equipe masculina, na categoria mirim, uma equipe masculina, categoria infantil e, por fim, uma equipe feminina, categoria infantil. A categoria mirim compreende a faixa etária de oito a dez anos. A categoria infantil compreende a faixa etária de onze a treze anos.

No início do ano, um acordo entre a direção da escola e os professores de educação física deliberou que o professor Jorge Wagner ficaria responsável pela seleção e treinamento das equipes masculina e feminina da categoria infantil, enquanto a professora Marta ficaria

\footnotetext{
${ }^{18}$ Os Jogos Estudantis são promovidos pela Prefeitura do Rio de Janeiro, cabendo sua organização e realização à Secretaria Municipal de Educação. Os Jogos Estudantis são destinados a alunos do ensino fundamental.

Wovimento, Porto Alegre, v. 16, n. 01, p. 71-96, janeiro/março de 2010.
} 


\section{Antigos Orifimais Antonio Jorge Gonçalves Soares et al.}

incumbida de selecionar e treinar a equipe masculina da categoria mirim. Cada equipe possui uma carga de treinamento semanal de uma hora e meia

Quando indagada sobre o processo de formação de equipes esportivas dentro da escola, a professora Marta mostrou-se insatisfeita com a situação vigente:

"O Jorge Wagner que monta as equipes da escola, inclusive ele deixa de dar dois tempos semanais de aula para dar treino para equipe de handebol. Ele queria que eu ficasse com a equipe mirim mas eu não acho justo tirar um tempo de aula das crianças para treinar equipe. Então eu pedi para o Jéferson, que é o melhor da equipe de cima, treinar os menores $[\ldots]$ Eu e o Jorge somos diferentes, eu prefiro dar aula e ele gosta mais de formação de equipes." (Diário de Campo, 25/10/2006).

"Eu não faço esse trabalho com equipes, quem faz é o Jorge. O Jorge Wagner vem trabalhando com Futsal e Handebol já algum tempo, ele queria que eu pegasse a equipe mirim de handebol [...] assim, eles iam crescendo e quando chegassem ao infantil eles já teriam uma noção. Eu falei para ele que eu ia tentar, pois eu nunca formei equipe [...] eu não gosto, eu acho que eu não estudei para ser técnica, a minha função é dar aula [...] eu não acho justo trabalhar com 10 alunos, enquanto o resto fica sentado sem aula. Eu combinei com aquele menino, Jéferson, para ele treinar a equipe para mim fora do horário das aulas, pois assim ninguém ia sair perdendo... parece que a equipe foi à final. Já o Jorge, eu não sei como ele trabalha. Eu acho que primeiro ele trabalha dentro da aula, ele vê os que têm mais habilidade e encaminha para a equipe [...] ele estava tirando um tempo de aula de uma turma para poder treinar, porque se não for assim não tem como você treinar. A escola Ceará trabalha com isso, eles fazem assim: eles têm oficinas, e dali eles tiram os alunos que têm maior habilidade para a coisa [...] aí manda para o professor específico daquela modalidade. Na minha opinião dentro da escola tem que ter três, quatro professores, quem gosta de treinar equipe, vai treinar, e deixa os outros com o trabalho de educação física." (Entrevista concedida pela professora Marta em 29/11/2006).

Vovimento, Porto Alegre, v. 16, n. 01, p. 71-96, janeiro/março de 2010. 
Percebemos que dentro da unidade escolar há divergências de opiniões quando o assunto é a formação e o treinamento de equipes esportivas para competições. De um lado, encontra-se o professor Jorge Wagner, que respaldado pela direção da escola, preconiza a formação de equipes e do outro a professora Marta que não concorda com o processo de formação e treinamento organizado na instituição. Aqui temos conflitos semelhantes aos encontrados por Trotte (2005) que verificou uma convivência tensa entre o grupo de professores que ministravam aulas com base nos esportes coletivos para a formação de equipes e um grupo de professores que buscavam inserir outros conteúdos relacionados à educação do corpo no espaço da educação física escolar. Esses conflitos entre os professores da disciplina se dão em função da forma como a comunidade escolar dialoga e decide parâmetros de atuação com a educação do corpo para o lazer e os conteúdos na escola.

De forma mais ampla, podemos pensar que esse conflito está ancorado na reflexividade do próprio campo de debates da educação física escolar. A professora Marta não é contra a proposta de formação esportiva dentro da escola, ela apenas não concorda com a forma como essa proposta vem se estruturando no tempo escolar dedicado à disciplina. Segundo a professora, a escola deve planejar-se de forma que determinadas turmas não tenham seus direitos cerceados à prática da aula de educação física, ou seja, a escola deve reservar horários fora da grade curricular, além de designar professores que possuam um real comprometimento com a proposta de formação esportiva de rendimento. Observe-se que apesar das ponderações da referida professora, suas aulas possuem baixa frequência.

Apesar de não termos observado diretamente os treinamentos das equipes esportivas da escola, pudemos obter, através dos depoimentos da professora e dos alunos, diversas informações sobre as motivações daqueles que integram as equipes. Abaixo, serão descritos trechos de depoimentos de alunos pertencentes às equipes esportivas da escola:

\footnotetext{
"Quando a gente chegou lá em São Januário para jogar a semifinal, todo mundo achou que ia tá cheio de olheiro [...] ainda mais sendo lá no Vasco.” (Informante 1).
}

Movimento, Porto Alegre, v. 16, n. 01, p. 71-96, janeiro/março de 2010. 


\begin{abstract}
"Quando a gente foi campeão da nossa área, todo mundo estava achando que o amigo do professor ia levar a gente para o clube dele, igual ele fez com as meninas." (Informante 2).

"As meninas nem ganharam nada e foram jogar em clube, a gente foi campeão, e o professor ainda não disse nada." (Informante 3).

"Falaram que as meninas iam até receber." (Informante 2).

"O professor falou que desses jogos já saiu gente para jogar em clube.” (Informante 3 ).
\end{abstract}

Percebemos nas falas desses alunos que eles veem as suas participações nas equipes esportivas da escola como uma possibilidade de profissionalização. ${ }^{19}$ Para eles, a presença nas equipes é uma forma de angariar prestígio interno e de sonhar com a ascensão social e econômica através do esporte. Independente dos efeitos positivos afirmados pelos alunos, observamos nesse cenário a confusão, sobreposição de tempos e espaços destinados à educação física e ao treino de equipes. Isso revela a ausência de acordos entre os professores responsáveis por esse tipo de formação corporal dos alunos no currículo escolar. Por outro ângulo, podemos pensar que as equipes esportivas, as oficinas de teatro ou de música e os concursos de literatura ou as olimpíadas de matemática representam no tempo escolar possibilidades de estimular talentos. Afinal, a escola não pode ter essa finalidade?

\title{
60 RECREIO E OS TEMPOS VAgOS
}

Durante o período de observação, constatamos que as atividades praticadas nesses "tempos" na escola Euzébio Bragança se relacionam com o esporte e com outras brincadeiras e jogos. Esses "tempos" são autoadministrados pelos alunos sem nenhuma mediação pedagógica. A escola não possui nenhum funcionário ou professor para controlar os problemas que possam decorrer destes "tempos vagos" de descon-

${ }^{19}$ Observe-se que não vemos a profissionalização no esporte como algo distinto do lazer, aqui não entendido como não-trabalho, mas como espaço de autoconstrução.

Movimento, Porto Alegre, v. 16, n. 01, p. 71-96, janeiro/março de 2010. 
tinuidade em relação às atividades das disciplinas, apenas no recreio uma funcionária observa os alunos. No recreio, por exemplo, verificamos a organização de quatro grupos. Na quadra organiza-se o grupo que joga futebol, enquanto nos espaços anexos a ela, outros três grupos organizam-se: o grupo da queimada, o grupo do "bobinho" (tipo de jogo com bola) e o grupo do tênis de mesa. O mecanismo de organização dos grupos durante o recreio, se adotarmos uma perspectiva de estranhamento, é algo que chama atenção e revela os jogos de hierarquia presentes entre os alunos. Ao chegar à quadra e aos espaços anexos a ela, os grupos se auto-organizam de forma mais rápida, se comparada à participação nas aulas de educação física. Nesse sentido, a professora Marta, que compartilhava conosco a observação dos alunos, comentou:

\footnotetext{
“Agora para eles é a melhor hora [referindo-se ao recreio], pode observar que não vai ter briga nenhuma [...] a gente nem precisa ficar aqui..' (Diário de campo, $31 / 10 / 2006)$.

"Agora é bom [referindo-se ao recreio] que eles não perturbam.” (Diário de campo, 09/11/2006).
}

A suposta organização pacífica, segundo a professora, pode apenas esconder outros conflitos que não são percebidos pela organização escolar. O processo de apropriação da quadra durante o recreio é estruturado a partir das relações de gênero e das cotas de poder entre grupos, na qual a faixa etária é determinante. $\mathrm{O}$ grupo dos "mais velhos", dos meninos, controla a ocupação e as ações dentro da quadra durante os horários destinados aos recreios para a prática do futebol. Os demais grupos não têm acesso à quadra durante esse intervalo de tempo, em função disso, utilizam os espaços anexos para a prática de suas atividades corporais. Observe que esse modelo de auto-organização do tempo nesses espaços são naturalizados pelos professores e funcionários responsáveis pela direção. Vejamos alguns depoimentos que nos ajudam a desvelar esse mecanismo:

"Você vai perceber que o grupo que joga é sempre o mesmo, são os mais fortes da escola que formam a espécie de um clã e não deixam ninguém entrar." (Diário de campo, 04/10/2006. Fala da professora Marta).

Movimento, Porto Alegre, v. 16, n. 01, p. 71-96, janeiro/março de 2010. 
"Essa ocupação da quadra no recreio é elitista e machista, só eles (referindo-se ao grupo do futebol) ficam nela durante o recreio. Ninguém pode ir lá dentro não.” (Diário de campo, 13/11/2006. Fala da diretora da unidade escolar).

"Os maiores não deixam a gente jogar não, até parece que a quadra é deles." (Diário de campo, 13/11/2006. Fala de um aluno pertencente ao grupo do "bobinho").

Nos tempos vagos, o modelo de organização é semelhante ao do recreio. As observações da diretora e da professora sobre a ausência de brigas e conflitos durante os recreios e tempos vagos, se contrabalançada com a fala do aluno acima, pode indicar que os conflitos e brigas são abafados pelas relações de poder estabelecidas nesse espaço entre os alunos a partir da faixa etária e das relações de gênero. O espaço é controlado pelos "mais velhos", é naturalizado de forma ritual, os mais jovens hoje são deslocados para o "corredor da quadra" ou para os espaços que sobram, amanhã, quando forem os "mais velhos" poderão assumir o poder de controlar a "quadra". Poderíamos perguntar: quando as crianças estão expostas à sua própria sorte para organizar o tempo e espaço não estão expostas às relações autoritárias que se estruturam a partir do poder desigual entre eles? Em outras palavras, sem a supervisão dos adultos - professores, inspetores e outros agentes educacionais - os jovens podem estar entregues a sua própria violência (ARENDT, 2005). Na escola observada, a "lei do mais forte" que se estrutura na ocupação do tempo e espaço dos "tempos" descontínuos com as aulas disciplinares parece encontrar eco nas relações travadas no entorno dos muros da escola e especificamente nas relações na comunidade em que residem.

\section{CONSIDERAÇÕES FINAIS}

Ao analisar a participação dos alunos nas aulas de educação física da escola Euzébio Bragança, percebemos que o espaço e o tempo das aulas de educação física não são identificados como um valor positivo, ao menos para uma grande parcela de alunos. Os motivos estão intrincados em uma teia complexa de relações, tensões e conflitos entre os atores da instituição escolar, a comunidade que acolhe a escola, diversi-

Wovimento, Porto Alegre, v. 16, n. 01, p. 71-96, janeiro/março de 2010. 
dade de valores sobre a formação do cidadão e da função da educação física neste contexto. De modo algum queremos declarar que conseguimos desvendar os mecanismos da caixa preta que explicam e solucionam tais relações, apenas apontar pistas que possibilitem entender os dilemas que a disciplina educação física enfrenta no tempo-espaço desta escola e, em alguma medida, em outras realidades próximas.

Nas aulas de educação física, o conteúdo principal abordado é o esporte. Verificamos um alto percentual de alunos presentes no espaço físico da aula que não participam (35,5\%). Se somarmos o número de alunos presentes e não-participantes ao número de alunos ausentes $(15,5 \%)$, chegamos a um valor de $51 \%$, ou seja, mais da metade dos alunos das turmas investigadas não é atendida pela disciplina educação física. A primeira vista, poderíamos simplesmente afirmar que o espaço da escola e, especificamente, das aulas de educação física não está sendo valorizado pelos alunos e alunas. Entretanto, tal afirmação não dá conta da teia de relações e conflitos enfrentados no cotidiano escolar. Estes alunos e alunas possuem em sua rotina de atividades diárias, as intensas e constantes incursões policiais que influenciam diretamente o funcionamento do comércio e demais instituições locais. Deste modo, a presença dos alunos é também o resultado da situação de confronto entre policiais e facções do tráfico. Mesmo com este panorama, um determinado grupo de alunos, pelos mais variados motivos, ocupa seu tempo no espaço escolar participando de todas as disciplinas do currículo.

Nas aulas de educação física, cerca de $35 \%$ dos alunos(as) optam por não participar de tais aulas alegando não estar com uniforme ou apenas não gostar da professora, do conteúdo e da disciplina. O argumento do uniforme é uma resposta socialmente aceita que conforma e justifica outras motivações dos atores e não nos permite avançar significativamente nas análises. Entretanto, as demais respostas dos alunos ilustram que a linguagem do gosto foi se impondo, sendo hoje a linguagem dominante para expressar a construção do eu e das motivações em nossas ações nesses espaços encarados fundamentalmente como locais de sociabilidade. Por outro lado, a experiência pedagógica declarada pela professora parece reforçar a não-adesão dos alunos(as) na medida em que aceita o gosto como um argumento justificador para

Movimento, Porto Alegre, v. 16, n. 01, p. 71-96, janeiro/março de 2010. 


\section{2}

Artifor Orifimais Antonio Jorge Gonçalves Soares et al.

a autoexclusão. Podemos indicar que existe uma espécie de diálogo, não explícito, sobre o papel dessa disciplina no tempo escolar que é travado nas interações cotidianas na escola. Somado a isto, podemos perceber tensões internas entre os próprios professores de educação física acerca da atuação e dos objetivos da disciplina. Estas tensões ficam mais visíveis quando o assunto em pauta são as equipes esportivas, elas devem ou não diferenciar-se da educação física prevista na grade curricular? Este quadro de conflitos e tensões a partir da educação física nos permite problematizar o papel da educação física na contemporaneidade. Esses espaços e tempos devem ter a participação compulsória dos alunos ou deve-se ordenar pela linguagem do gosto?

O problema é que a educação física, apesar de sua longa tradição no espaço e tempo da escola moderna, ainda carece de acordos mínimos sobre seus objetivos na formação das novas gerações. O pior é que parece que estamos caminhando exatamente no sentido contrário da busca da pretendida legitimidade da disciplina debatida ardentemente na década de 1980. No esforço de estimular a participação ou aceitar a não-participação dos alunos com base no gosto, deixamos de lado um princípio fundamental: a aula é um espaço e tempo de transmissão de conhecimento, valores e habilidades de forma intencional e sistemática.

Desta forma, os argumentos justificadores da autoexclusão dos alunos com base na linguagem do gosto ganham força e acabam gerando um efeito perverso do espaço-tempo das aulas. Alunos e professores, ao incorporarem essa linguagem, sem considerar outras funções da instituição educativa, acabam entendendo a disciplina de educação física como um espaço de prática quase optativa.

Nos tempos vagos e recreios, os alunos, do sexo masculino e mais velhos, possuem mais possibilidades de fruição corporal nos jogos e brincadeiras que são realizadas na quadra central. A forma de ocupação desse local se dá na medida em que não existe mediação pedagógica nesses tempos e espaços da escola. Sendo assim, os pequenos espaços para realizar atividades por aqueles que são mais novos ou do sexo feminino ficam restritos ao que sobra no entorno da quadra principal. Devemos refletir, se queremos uma sociedade mais igualitária,

Movimento, Porto Alegre, v. 16, n. 01, p. 71-96, janeiro/março de 2010. 
que os tempos e espaços para socialização de conhecimentos ou de experiências de sociabilidade deveriam se tornar um objeto de reflexão pedagógica no interior das escolas. O que acontece no pátio pode ter alguma interferência na formação de subjetividades dos futuros cidadãos.

Movimento, Porto Alegre, v. 16, n. 01, p. 71-96, janeiro/março de 2010. 


\section{Astigor Originair Antonio Jorge Gonçalves Soares et al.}

\begin{tabular}{l}
\hline Time and space for education in the daily body of \\
a public school \\
Abstract: This article's objective is to analyze the pos- \\
sibilities of corporal education during the physical edu- \\
cation classes, practices, school break and free time in \\
a public school in Rio de Janeiro. For that we interviewed \\
the students and observed them during classes, free \\
time and school break. The analysis of the articles indi- \\
cates that the classes are identified by the students as a \\
positive value, at least for some of them. The motives of \\
the devaluation are linked in a complex net of tension bet- \\
ween the members of the school, the school community, \\
diversity of values about the citizen's formation and pur- \\
pose of the physical education. \\
Keywords: Observation. Motivation. Physical education.
\end{tabular}

Tiempo y espacio para la educación en el cuerpo a diario de una escuela pública

Resumen: El objetivo es analizar las posibilidades de la educación corporal en el espacio y el tiempo en las clases de educación física, treinos, recreos y tiempos vagos en una escuela pública en Rio de Janeiro. Se realizó la observación de las clases, recreos y tiempos vagos y entrevistas con los estudiantes y el profesor. Se concluye que el espacio y el tiempo de clases no son identificados como valor positivo, al menos para gran parte de los estudiantes. Las razones son una intrincada red de complejas tensiones entre los actores de la escuela, que acoge a la comunidad escolar, la diversidad de valores en la formación de los ciudadanos y "función" de educación física.

Palabras clave: Observación. Motivación. Educación Física.

\section{REFERÊNCIAS}

ARENDT, H. Hannah Arendt: entre o passado e o futuro. 5. ed. São Paulo: Perspectiva, 2005.

BASSANI, J. J; TORRI, D; VAZ, A. F. Educação do corpo, esporte e Educação física escolar. Revista Virtual EFArtigos, Natal, v.2, n. 24,abr. 2005. Disponível em: http:// efartigos.atspace.org/efescolar/artigo38.html. Acesso em: 10 nov. 2007.

BOYLE, R; HAYNES, R. Power Play: sport, the media and popular culture. Edinburgh Gate: Pearson Education, 2000.

BOURDIEU. P. Coisas ditas. São Paulo, Brasiliense, 1990

Movimento, Porto Alegre, v. 16, n. 01, p. 71-96, janeiro/março de 2010. 
BRASIL. Ministério da Educação. Secretaria de Educação Fundamental. Parâmetros curriculares nacionais: Educação Física, Brasília: MEC /SEF, 1998.

BRASÍLIA. Secretaria de Educação Fundamental. Parâmetros Curriculares Nacionais: Educação Física. Brasília: MEC/SEF, 1998.

CALADO, M. C. Proposta pedagógica para reduzir o índice de absenteísmo dos alunos de ensino médio do Centro Federal de Educação Tecnológica do Espírito Santo na disciplina Educação Física. Dissertação (Mestrado). Vitoria: CEFET, 2003.

COSTA, R. C. M. M. A educação física no CETEP Marechal Hermes: um estudo do cotidiano escolar. 2004. Dissertação (Mestrado) - Universidade Gama Filho, Rio de Janeiro, 2004.

CUCHE, D. A noção de cultura nas ciências sociais. 2. ed. São Paulo: EDUSC, 2002.

DARIDO, S. Educação Física na escola: questões e reflexões. Rio de janeiro: Guanabara Koogan, 2003.

FARIA FILHO, L. M.; VIDAL, D. G. Os tempos e os espaços no processo de instucionalização da escola primária no Brasil. Revista Brasileira de Educação, Rio de Janeiro, v.14, n.32, p. 19-34, maio/ago. 2000.

DIETRICH, K.; DÜRRWÄCHTER, G; SCHARLLER, H. J. Os grandes jogos metodologia e prática. Rio de Janeiro: Ao livro Técnico. 1984.

GHIRALDELLI JUNIOR, P. A Educação Física progressista: A pedagogia críticosocial dos conteúdos e a educação física brasileira. São Paulo: 1989.

KANT, Emmanuel. A crítica da razão pura. Rio de Janeiro: Tecnoprint, 1971.

KUPPER, A. Cultura: a visão dos antropólogos. São Paulo: EDUSC, 2002.

LOVISOLO, H. Estética, esporte e educação física. Rio de Janeiro: Sprint, 1997.

Saúde, educação e educação física. Rio de Janeiro: Sprint, 2000.

Tédio e espetáculo esportivo. In: ALABARCES, P. (Org). Futbologias: Buenos Aires: Clacso, 2003. p. 241-255.

LUCAS, B. B. A educação física e a formação corporal em uma escola progressista: um olhar etnográfico. 2004. Dissertação (Mestrado) - Universidade Gama Filho, Rio de Janeiro, 2004.

LUCERO, F. A opinião dos alunos do $3^{\circ}$ e $4^{\circ}$ ciclos do ensino fundamental acerca da educação física escolar. 2005. Dissertação (Mestrado) - Universidade Gama Filho, Rio de Janeiro, 2005.

MACEDO, E. Currículo como espaço-tempo de fronteira cultural. Revista Brasileira de Educação, Rio de Janeiro, v.11, n.32, p.287-372, maio/ago. 2006.

Movimento, Porto Alegre, v. 16, n. 01, p. 71-96, janeiro/março de 2010. 


\section{Antigor Orifinais Antonio Jorge Gonçalves Soares et al.}

PETITAT, A. A escola e a produção da sociedade. Educação e Realidade, Porto Alegre, v.14, n.2, p.21-30, jul./dez. 1989.

SABINO, C. Anabolizantes: drogas de Apolo. In: GOLDENBERG, M. (Org.). Nú e vestido: dez antropólogos revelam a cultura do corpo carioca. Rio de Janeiro: Record, 2002

SIMMEL, G. Questões fundamentais da sociologia. Rio de Janeiro: Jorge Zahar, 2006.

TROTTE, S. M S. A Educação Física e o projeto político pedagógico do Colégio Estadual Visconde de Cairú: proximidade ou distanciamento? 2005. Dissertação (Mestrado) - Universidade Gama Filho, Rio de Janeiro, 2005.

Pesquisa com Financiamento do CNPq - Conselho Nacional de Desenvolvimento Científico e Tecnológico

Recebido em: 19.02.2008

Aprovado em: 24.10.2008

Movimento, Porto Alegre, v. 16, n. 01, p. 71-96, janeiro/março de 2010. 